\title{
Spontaneous pneumothorax as unusual presenting symptom of COVID-19 pneumonia: surgical management and pathological findings
}

\author{
Roberto Bellini ${ }^{1+}$, Maria Chiara Salandini ${ }^{1^{*+}} \mathbb{D}$, Serena Cuttin ${ }^{2}$, Stefania Mauro ${ }^{3}$, Paolo Scarpazza ${ }^{4}$ and \\ Christian Cotsoglou ${ }^{1}$
}

\begin{abstract}
Background: Spontaneous pneumothorax has been reported as a possibile complication of novel coronavirus associated pneumonia (COVID-19). We report two cases of COVID-19 patients who developed spontaeous and recurrent pneumothorax as a presenting symptom, treated with surgical procedure. An insight on pathological finding is given.

Case presentation: Two patients presented to our hospital with spontaneous pneumothorax associated with SarsCov2 infection onset. After initial conservative treatment with chest drain, both patients had a recurrence of pneumothorax during COVI-19 disease, contralateral (patient 1) or ipsilateral (patient 2) and therefore underwent lung surgery with thoracoscopy and bullectomy. Intraoperative findings of COVID-19 pneumonia were parenchymal atelectasis and vascular congestion. Lung tissue was very frail and prone to bleeding.

Histological examination showed interstitial infiltration of lymphocytes and plasma cells, as seen in non specific interstitial pneumonia, together with myo-intimal thicknening of vessels with blood extravasation and microthrombi.

Conclusions: Although rarely, COVID-19 may present with spontaneous pneumothorax. Lung surgery for pneumothorax in COVID-19 patients can be safely and effectively performed when necessary.
\end{abstract}

Keywords: Pneumothorax, COVID-19, Thoracoscopy, Case report, Bullectomy, Pathology

\section{Introduction}

On December 2019, a novel coronavirus-related pneumonia has been first reported in the city of Wuhan, China [1]. Since then, the disease has spread worldwide throughout Asia, Europe, America and Africa. In Italy, the first cases of novel coronavirus infections were reported on February 21, 2020.

\footnotetext{
*Correspondence: mariachiara.salandini@asst-vimercate.it

${ }^{\dagger}$ Roberto Bellini and Maria Chiara Salandini contributed equally to this work. 'Department of Surgery, General Surgery Division, Vimercate Hospital, Vimercate, Italy

Full list of author information is available at the end of the article
}

Patients with COVID-19 can have mild symptoms such as fever, cough, fatigue and smell and taste dysfunction, or more serious and rapidly progressing respiratory impairment such as Acute Respiratory Distress Syndrome [2,3].

Radiological presentation at CT scan is characterized by bilateral interstitial infiltrates with ground glass opacities (GGO), multiple lobar and subsegmental consolidations and air bronchograms [4]. Other findings such as pleural effusion, cavitation, pneumomediastinum and pneumothorax are uncommon and in some cases anecdotal [4-6]. 
Pneumothorax is often a late manifestation of the disease, mainly due to patient intubation and positive airpressure oxygen administration [7].

We describe two cases of spontaneous pneumothorax (SP) as presenting symptom of COVID-19 disease and their surgical management, with insight on intraoperative and pathological findings.

\section{Case 1}

A 58-year-old male presented to the Emergency Department of our hospital on March 22 for sudden right thoracic pain, dyspnea, and mild fever. He was a former smoker, with no significant medical history. At presentation, he had tachycardia and hypertension (heart rate 120, blood systemic pressure 190/120), tachypnea and desaturation (respiratory rate $40 / \mathrm{min}$, arterial blood saturation $81 \%$ ). At hemogasanalysis, $\mathrm{pH}$ was 7.38 , paO2 was 53 $\mathrm{mmHg}$ and $\mathrm{paCO} 244 \mathrm{mmHg}$. Chest X-ray showed massive right pneumothorax (Fig. 1a): a 20 Ch chest drain was positioned, with immediate relief of patient dyspnea and normalization of vital parameters. Post-procedural Xray showed full re-expansion of the lung. Blood tests revealed mild leukocytosis with lymphopenia, slight lactate dehydrogenase (LDH) elevation, normal C-reactive protein (CRP). A CT scan showed bilateral interstitial pneumonia with GGO and air bronchograms, suggesting COVID-19 disease. Oropharyngeal swab test was positive for Sars-CoV2.

The patient was treated with broad spectrum antibiotics (ceftriaxone and azythromycin), hydroxychloroquine, intra venous fluids, and nasal high-flow rate oxygen. Chest drain was removed on day 5 , after seeing gradual regression of pulmonary infiltrates and no recurrence of pneumothorax at follow-up X-ray. The patient was discharged 3 days later.

Twenty-eight days later the patient was readmitted to our hospital for sudden dyspnea and chest pain. Chest Xray showed left (contralateral) massive pneumothorax. A $20 \mathrm{CH}$ chest tube was inserted, with subsequent pulmonary re-expansion (Fig 1b). A second oropharyngeal test was positive for COVID-19. Because of the bilateral occurrence of massive pneumothorax, he was a candidate for surgery. On April 24 the patient underwent left thoracoscopy with multiple pulmonary resections of dystrophic areas and mechanical pleurodesis by surgical pleural scarification and partial pleurectomy along costal arches, from the 3rd to the 7th rib. A single chest drain was left and then removed on postoperative day (POD) 6 . The patient was discharged the day after, when routine control chest $\mathrm{X}$-ray showed no recurrence of pneumothorax.

\section{Case 2}

A 53-year-old female presented to the Emergency Department with a three-day history of cough, fever, right chest pain and hemoptysis. The patient had a medical history of blood hypertension, and she was a non smoker. Chest X-ray showed right $35 \mathrm{~mm} \mathrm{SP}$, that extended from the apex to the basal edge of the lung, together with bilateral pulmonary infiltrates, suggestive of COVID-19 disease. A $20 \mathrm{Ch}$ left chest drain was inserted in 5th intercostal space, and post-procedural X-ray showed complete re-expansion of the lung. After positioning, no persistent air loss was seen from the drain. Blood tests revealed normal white blood cell count with slight elevation of LDH and CRP. Hemogasanalysis revealed moderate hypoxhemia, with a paO2 level of 67 $\mathrm{mmHg}$, with low carbon dioxide levels (paCO2 25 $\mathrm{mmHg}$ ) and mild alkalosis ( $\mathrm{pH} 7.48$ ). Oropharyngeal swab test was positive for Sars-CoV2. Chest CT scan showed basal bilateral confluent GGOs with small consolidative opacities, and an $18 \mathrm{~mm}$ bulla located at the apical segment of the right lower lobe, within a GGO area (Fig. 1c and d).

The patient was treated with oral hydroxychloroquine, antibiotic therapy with piperacillin-tazobactam, and high flow nasal oxygen.

Chest drain was kept in place with no air loss for a few days, and then removed on day 5. Unexpectedly, routine control chest $\mathrm{X}$-ray before discharge revealed a $35 \mathrm{~mm}$ recurrence of right pneumothorax.

Because of the recurrence of pneumothorax, and the consequent risk of adding further respiratory distress in a COVID-19 pneumonia, the patient was a candidate for surgery. Surgical procedure was performed with right dual-port thoracoscopy and consisted in double pulmonary resections (i.e. apicectomy and resection of apical segment of lower lobe) with mechanical pleurodesis by surgical pleural scarification and partial pleurectomy from the 3rd to the 7th costal arch. A single chest drain was left and then removed on POD 6. After removal, control Xray showed no recurrence of pneumothorax. During the following days, the patient experienced recurrence of fever with mild elevation of white blood cell count, although both chest X-ray and hemogasanalysis did not show deterioration of pneumonia. Therefore, the patient was treated with symptomathic therapy, until spontaneous regression of the fever and normalization of white blood cell count occurred. She was discharged on POD 12.

\section{Discussion}

Pneumothorax, usually due to prolonged ventilation with positive pressure, is a relatively common complication of COVID-19 pneumonia, affecting up to $5.9 \%$ of patients [7].

In 2004, Sihoe et al. reported a $1.7 \%$ incidence of SP in Severe Acute Respiratory Syndrome (SARS) patients [8]. In this series, pneumothorax was a late complication of SARS, occurring from 14 to 37 days after initial diagnosis, suggesting that a sustained period of lung inflammation is first required. Four patients were treated with 


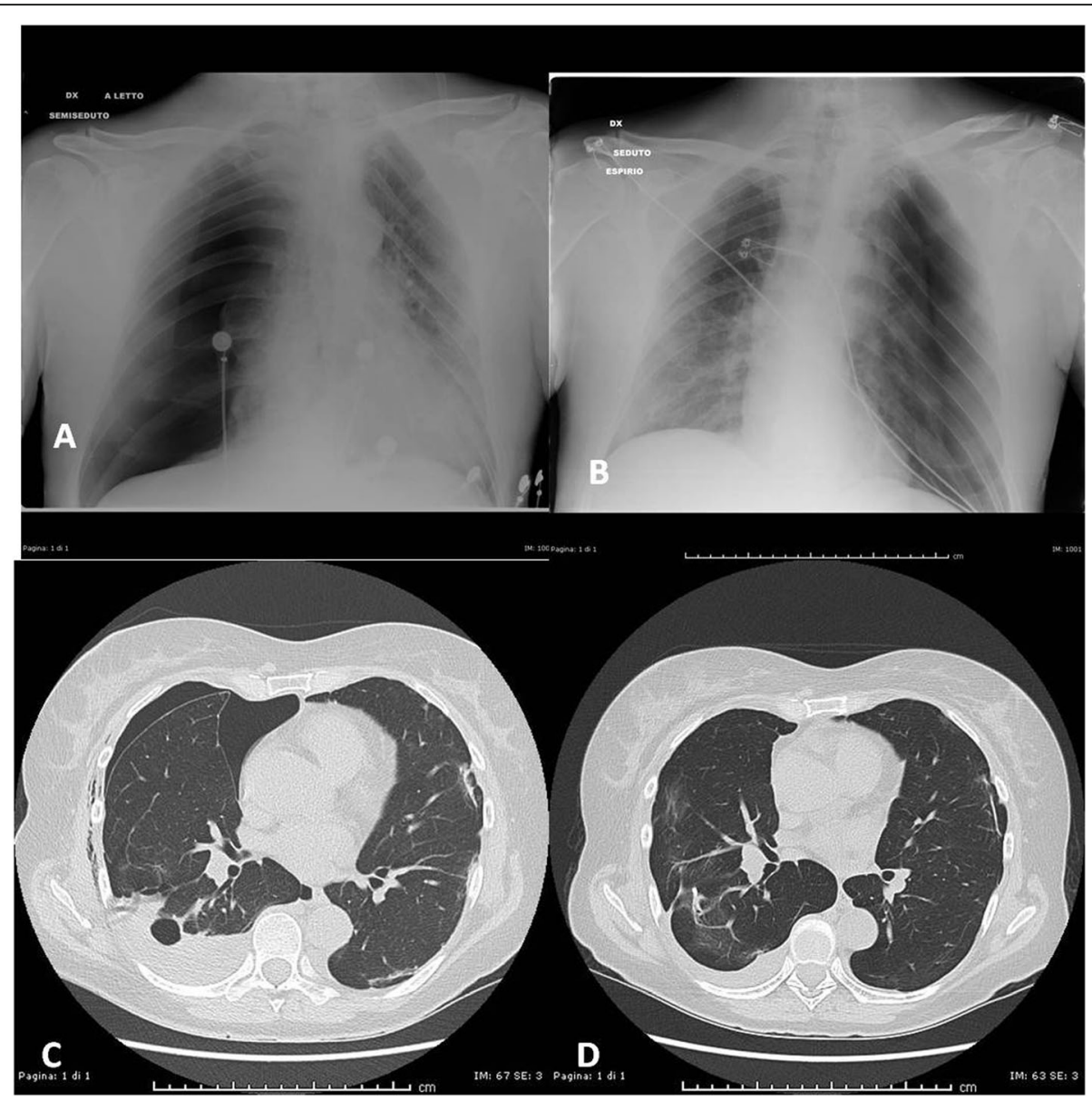

Fig. 1 Chest X-ray showing massive left (a) and right (b) pneumothorax in COVID-19 patient 1; preoperative CT scan showing right pneumothorax with bulla of the apical segment of the lower lobe (c) and ground glass opacities (d) typical of COVID-19 disease in patient 2

chest drain, and two were managed conservatively. Chest drains were removed from 14 up to 31 days after insertion: permanence of drains was mainly due to prolonged air loss. None of the patients underwent surgical operation because of both severe impairment of patient's lung function and high anesthetic risk, and because of concern for infection risk to operating room staff [8].

As for novel coronavirus disease, other authors have already reported SP as a clinical manifestation for COVID-19 [4, 5, 9, 10]; however, none of them was managed with a surgical approach.

Tian and colleagues [11] reported of two patients submitted to pulmonary lobectomy for lung cancer who developed fever and respiratory failure after surgery: a postoperative oropharyngeal swab test revealed a Sars$\mathrm{CoV} 2$ infection. A review of preoperative CT scan revealed bilateral GGOs in one of them, while the second developed radiologically detectable interstitial pneumonia on POD 2. This is actually the first report of COVID-19 patients with lung pneumonia submitted to lung surgery.
We report the first two cases of patients with novel coronavirus pneumonia with SP as presenting symptoms who were surgically treated.

Our first approach for both patients was chest drain, because we had no knowledge of whether COVID-19 could favor complications after surgery. However, after recurrence of SP in both patients we had to consider surgical treatment because of the need to avoid possible further respiratory distress in patients with ongoing interstitial pneumonia.

Intraoperative findings were of segmental and subsegmental areas characterized by atelectasis and vascular congestion, which proved to be very frail at manipulation and traction. These areas corresponded to GGO infiltrates at preoperative CT scan (Figs. 1 and 2). In particular, the rupture of the bulla at the apical segment of right lower lobe within an area of important vascular congestion and pulmonary atelectasis was probably the cause of patient 2 hemoptysis before hospital admission (Fig. 1c). 


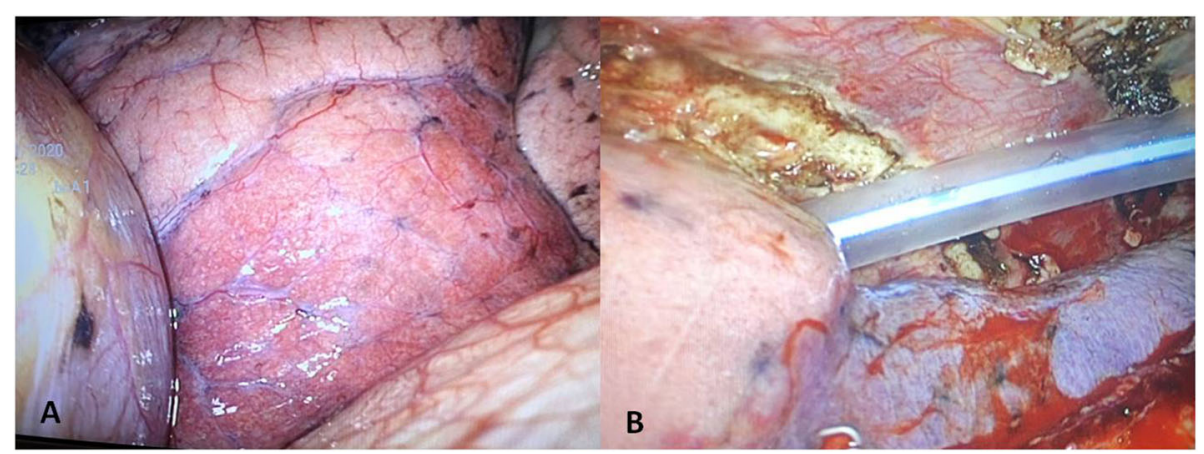

Fig. 2 Intraoperative finding of parenchymal vascular congestion and atelectasis in patient 1 (a) and in patient 2 in the site of bullectomy at the apical segment of lower lobe (b)

Notably, despite regular coagulation parameters and no anticoagulant therapy, both patient had a tendency for bleeding during gentle manipulation, so that we preferred not to perform extensive pleural scarification. This finding may be explained by systemic inflammation, which can impair proper coagulation [12].

Finally, during pulmonary re-ventilation at the end of the procedure, the COVID-19 atelectasis areas did not re-expand as expected, due to loss of parenchymal compliance, despite the use of positive pressure air flows.

At histological specimen evaluation the main finding was an interstitial pneumonia with ongoing reparative processes, associated with vascular changes probably responsible for increased vascular resistance. In particular, intense, diffuse and uniform chronic inflammation was located in the septal interstitium, with prevalence of lymphocytes and plasma cells, as typically found in non specific interstitial pneumonia. Extensive endoalveolar fibroblastic overhangs located in the centrolobular seat were retrieved. Alveolar spaces were filled with rare alveolar macrophages and proteinaceous exudates. Signs of viral infection consisted of nuclear pseudoinclusions, indicating cytopathic effects.
Vascular changes were of multiple and extensive interstitial and endoalveolar blood extravasations, and marked myo-intimal thickening with associated blood stasis, sometimes with microthrombi. Subendothelial infiltration of lymphocytes, suggestive of endotelitis, was also retrieved (Fig. 3).

Lastly, areas of distal emphysema and subpleural bullous formations with hemorrhagic content were also observed.

These findings are comparable to what Tian has described [11].

Although other authors have described SP as a clinical manifestation of SARS-Cov2 infection, this is the first report of diagnosed COVID-19 patients who underwent surgical treatment for spontaneous pneumothorax: intraoperative findings of rotten bulla in a COVID area explained why conservative treatment had failed in patient 2 , as well as similar findings of dystrophic and fragile parenchyma within COVID areas for patient 1 .

Differently from SARS patients [8], in these cases pneumothorax was the first symptom of COVID-19 and occurred at the beginning of pneumonia. Moreover, none of them experienced severe respiratory impairment

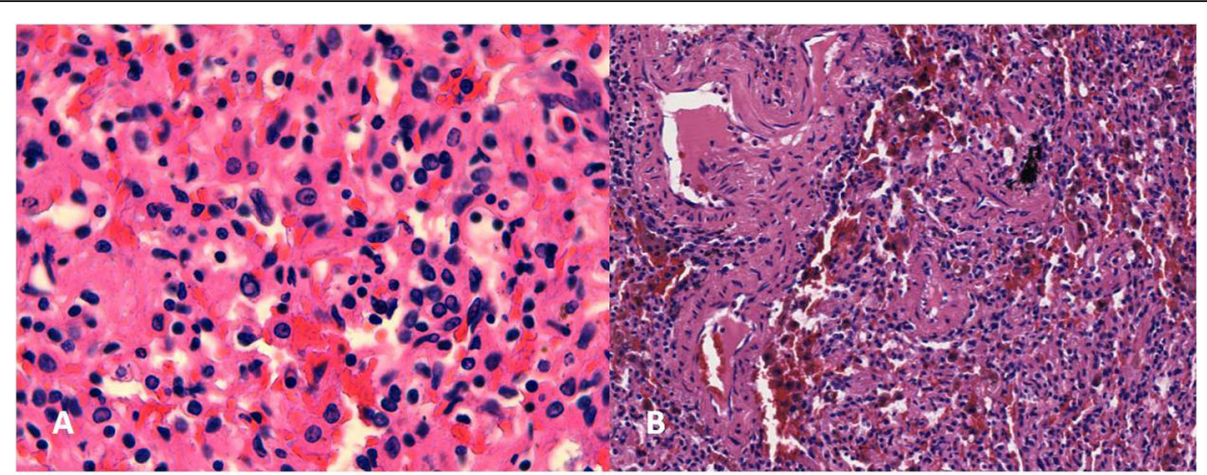

Fig. 3 Histological specimen. EE 400x viral cytopathic effects: nuclear pseudoinclusions (a). EE 200x vascular microthrombi associated with reduction of vascular lumen $(\mathbf{b})$ 
requiring invasive ventilation. This fact may reflect a different mechanism of pneumonia, where lung rupture does not occur as a final stage of prolonged inflammation, but is an immediate consequence of virus infection in selected patients: microvessel inflammation and capillary wall thickening at the early stages of the disease may play a significant role in this process, for which further studies are needed.

Despite understandable concerns for staff safety, all operative room members wore personal protection equipment as recommended by Italy SSI [13] and none of them developed COVID-19 infection. At 1 month follow up, all staff workers were COVID-19 IgG-free.

\section{Conclusions}

Spontaneous pneumothorax is a possible manifestation of COVID-19 disease.

When conservative treatment fails, surgery can be safely and effectively performed in COVID-19 patients with mild respiratory impairment.

\section{Abbreviations \\ COVID-19: Novel coronavirus associated pneumonia; GGO: Ground glass opacity; SP: Spontaneous pneumothorax; LDH: Lactate dehydrogenase; CRP: C-reactive protein; SARS: Severe acute respiratory syndrome; POD: Postoperative day}

\section{Acknowledgements}

We would like to thank Mrs. Katrina Anne Malcom for her precious help in editing this work.

\section{Authors' contributions}

Roberto Bellini and Maria Chiara Salandini contributed equally to this work. The author(s) read and approved the final manuscript.

\section{Funding}

No source of funding was used in the preparation of this manuscript.

\section{Availability of data and materials}

Not applicable.

\section{Ethics approval and consent to participate}

Not applicable.

\section{Consent for publication}

All patients involved provided written consent to use clinical information for scientific publications.

\section{Competing interests}

The authors have no conflict of interest to disclose.

\section{Author details}

${ }^{1}$ Department of Surgery, General Surgery Division, Vimercate Hospital, Vimercate, Italy. ${ }^{2}$ Department of Pathology, Vimercate Hospital, Vimercate, Italy. ${ }^{3}$ Milan Study University, Milan, Italy. ${ }^{4}$ Department of Pneumology, Vimercate Hospital, Vimercate, Italy.

Received: 31 July 2020 Accepted: 28 September 2020

Published online: 12 October 2020

\section{References}

1. Zhu N, Zhang D, Wang W, et al. A novel coronavirus from patients with pneumonia in China. New Eng J Med. 2020;382(8):727-33.
2. Giacomelli A, Pezzati L, Conti F, et al. Self-reported olfactory and taste disorders in SARS-CoV-2 patients: a cross-sectional study. Clin Infect Dis. 2020. https://doi.org/10.1093/cid/ciaa330.

3. Rodriguez-Morales AJ, Cardona-Ospina JA, Gutiérrez-Ocampo E, et al. Clinical, laboratory and imaging features of COVID-19: a systematic review and meta-analysis. Travel Med and Inf Dis. 2020;34:101623.

4. Salehi S, Abedi A, Balakrishnan S, Gholamrezanezhad A. Coronavirus disease 2019 (COVID-19): a systematic review of imaging findings in 919 patients. Am J Roentgenol. 2020:1-7.

5. Rohailla S, Najma A, Gough K. SARS-CoV-2 infection associated with spontaneous pneumothorax. CMAJ. https://doi.org/10.1503/cmaj.200609.

6. Zhou C, Gao C, Xie Y, Xu M. COVID-19 with spontaneous pneumomediastinum. Lancet Infect Dis. 2020;20(4):510.

7. Yao W, Wang T, Jiang B, et al. Emergency tracheal intubation in 202 patients with COVID-19 in Wuhan, China: lessons learnt and international expert recommendations. Br J Anaesth. 2020;125(1):E28-37.

8. Sihoe $A D$, Wong $R H$, Lee $A T$, et al. Severe acute respiratory syndrome complicated by spontaneous pneumothorax. Chest. 2004;125:2345-51.

9. Wang W, Gao R, Zheng Y, Jiang L. COVID-19 with spontaneous pneumothorax, pneumomediastinum and subcutaneous emphysema. J Travel Med. 2020;27(9):taaa062. https://doi.org/10.1093/jtm/taaa062.

10. Sun R, Liu H, Wang X. Mediastinal emphysema, Giant Bulla, and pneumothorax developed during the course of COVID-19 pneumonia. Korean J Radiol. 2020;21(5):541-4.

11. Tian S, Hu W, Niu L, Liu H, Xu H, Xiao S. Pulmonary pathology of early-phase 2019 novel coronavirus (COVID-19) pneumonia in two patients with lung Cancer. J Thorac Oncol. 2020;15(5):700-4.

12. Connors JM, Levy JH. COVID-19 and its implications for thrombosis and anticoagulation. Blood. 135(23):2033-40. https://doi.org/10.1182/blood. 2020006000.

13. Istituto Sanità Interim guidance for rational use of SARS-COV-2 infection protections in health and socio-health activities in the current SARSCOV-2 emerging scenario. Version of May 10, 2020. ISS Working Group COVID-19 Infections prevention and control 2020, ii, 17 p. Rapporto ISS COVID-19 n. 2/ 2020Rev. 2 (in Italian). https://www.epicentro.iss.it/coronavirus/pdf/rapportocovid-19-2-2020.pdf.

\section{Publisher's Note}

Springer Nature remains neutral with regard to jurisdictional claims in published maps and institutional affiliations.
Ready to submit your research? Choose BMC and benefit from:
- fast, convenient online submission
- thorough peer review by experienced researchers in your field
- rapid publication on acceptance
- support for research data, including large and complex data types
- gold Open Access which fosters wider collaboration and increased citations
- maximum visibility for your research: over $100 \mathrm{M}$ website views per year
At BMC, research is always in progress.
Learn more biomedcentral.com/submissions 